\title{
Chronic widespread musculoskeletal pain, fatigue, depression and disordered sleep in chronic post- SARS syndrome; a case-controlled study
}

Harvey Moldofsky ${ }^{1 *}$, John Patcai ${ }^{2,3}$

\begin{abstract}
Background: The long term adverse effects of Severe Acute Respiratory Syndrome (SARS), a viral disease, are poorly understood.

Methods: Sleep physiology, somatic and mood symptoms of 22 Toronto subjects, 21 of whom were healthcare workers, (19 females, 3 males, mean age $46.29 \mathrm{yrs} .+$-1 11.02) who remained unable to return to their former occupation (mean 19.8 months, range: 13 to 36 months following SARS) were compared to 7 healthy female subjects. Because of their clinical similarities to patients with fibromyalgia syndrome (FMS) these post-SARS subjects were similarly compared to 21 drug free female patients, (mean age $42.4+/-11.8$ yrs.) who fulfilled criteria for fibromyalgia.

Results: Chronic post-SARS is characterized by persistent fatigue, diffuse myalgia, weakness, depression, and nonrestorative sleep with associated REM-related apneas/hypopneas, an elevated sleep EEG cyclical alternating pattern, and alpha EEG sleep anomaly. Post- SARS patients had symptoms of pre and post-sleep fatigue and post sleep sleepiness that were similar to the symptoms of patients with FMS, and similar to symptoms of patients with chronic fatigue syndrome. Both post-SARS and FMS groups had sleep instability as indicated by the high sleep EEG cyclical alternating pattern rate. The post-SARS group had a lower rating of the alpha EEG sleep anomaly as compared to the FMS patients. The post-SARS group also reported less pre-sleep and post-sleep musculoskeletal pain symptoms.
\end{abstract}

Conclusions: The clinical and sleep features of chronic post-SARS form a syndrome of chronic fatigue, pain, weakness, depression and sleep disturbance, which overlaps with the clinical and sleep features of FMS and chronic fatigue syndrome.

\section{Background}

In light of public health concerns about the adverse effects of the recent $\mathrm{H} 1 \mathrm{~N} 1$ pandemic viral infection, it is noted that the long-term effects on survivors of those who survive severe illness are unknown. In this paper we report the results of our study of the long term adverse effects of Severe Acute Respiratory Syndrome (SARS) that emerged from South East Asia in early 2003 as the first contemporary novel severe acute infectious global health problem. In North America, Toronto experienced the bulk of cases that largely affected health care workers [1]. The Ontario

\footnotetext{
* Correspondence: h.moldofsky@utoronto.ca

${ }^{1}$ Sleep Disorders Clinic of the Centre for Sleep and Chronobiology, 340

College St., Suite 580, Toronto, ON M5T 3A9, Canada

Full list of author information is available at the end of the article
}

health authorities alerted health care personnel on March 14, 2003 about 4 family members with atypical pneumonia that resulted in two deaths. A province-wide emergency was declared on March $26^{\text {th }}$, 2003 when it became evident that these cases were the epidemiological link to SARS. The government and health care providers took steps to contain the spread of SARS by enacting infection control procedures, screening and isolating those people who were exposed, and admitting affected personnel, many of whom were health care workers, to special hospital SARS units. The public health precautions proved effective enough that by June 12, 2003 there were no more new cases. During those 3 months 273 people were identified as being confirmed SARS [2] cases. 44 [3] died. Because identification of victims and containment were the orders of the

\section{C) Biomed Central}


time, medical attention focused upon the features of the acute phase of the illness. They were identified as having new onset of fever, documented elevated temperature, and were likely to have nonproductive cough, myalgia, and dyspnea. Such individuals may have been exposed to patients who had traveled to a location known to harbour such cases, i.e., South China, South East Asia, or may have acquired these symptoms as the result of direct contact or exposure $[1,4]$. Subsequently a novel coronavirus was identified as the cause of the acute outbreak [5-7].

Although the epidemic in Toronto was considered controlled because no new cases appeared after June 2003 with no one remaining in quarantine $[1,8]$ one year later when life in the hospitals and city had returned to normal, a cohort of post-SARS patients remained disabled and unable to return to their work. They complained of persisting debilitating physical symptoms including variable musculoskeletal pain, profound weakness, easy fatigability, shortness of breath that accompanied psychological distress and major sleep problems. Because of the possibility of persistence of sleep-related respiratory dysfunction and arousal disturbances in the sleep EEG that could affect daytime fatigue and mood disturbances in the patients with the greatest clinical sleep disturbances, we examined their sleep physiology and coincident somatic and psychological symptoms. This is the first report of the long-term adverse effects of SARS on sleep and somatic symptoms.

\section{Methods}

The University Health Network human research ethics board approved the retrospective study of clinically necessary sleep studies, and signed informed consent forms were obtained from all patients. 19 females (mean age $46.29+/-11.02 y$., BMI $=28.26+/-6.88$ ) and 3 males, (all except one being health care workers) were assessed about 19.8 months after onset of the acute SARS illness (range: 13 to 36 months) with hospitalization and/or quarantine for SARS. They were part of a cohort of 50 post-SARS patients who had come under the care of the Ontario Workers' Safety and Insurance Board (WSIB) because of persistent impaired health that interfered with their hospital work capabilities. They had been sent by WSIB for a complex, intense, interdisciplinary clinical program of physical and psychological restorative rehabilitation. This post-SARS group was compared to a small group of younger healthy 8 females (mean age $30+/-6.7$ y., $\mathrm{p}=0.0002$ ), but with a similar BMI $(24.8+/-6.1, \mathrm{p}=.242)$ by employing standard self-ratings of physical symptoms [the Wahler Physical Symptom Inventory (WPSI)] [9], of depression [Beck Depression Inventory (BDI)] [10,11], of self rated symptoms of post traumatic stress disorder (PTSD) because of their exposure to the threat of death as the result of their exposure to the SARS virus[PTSD check list civilian version (PCL-
C)] [12], and of sleep symptoms [the Sleep Assessment Questionnaire $^{\mathrm{c}}\left(\mathrm{SAQ}^{\mathrm{c}}\right)$ ] [13]. The SAQ is a 17-item questionnaire that has been found to be useful for identifying sleep disorders related to chronic fatigue. One overnight polysomnography was employed in order to objectively evaluate sleep physiology. The procedures included electroencephalogram (EEG C3, C4) electro-oculogram, submental and bilateral anterior tibialis electromyogram, single anterior lead electrocardiogram, measures of respiration comprising measures of airflow with oralnasal thermistors and respiratory impedance plethysomography, and pulse oximetry. An experienced registered polysomnographic technologist completed blind ratings of sleep physiological indices [14] and standardized ratings ( 1 to 5 ) of the presence of a measure of arousal in the non rapid eye movement sleep EEG (NonREM sleep), known as the alpha frequency anomaly [15] where 1 was the percentage of alpha EEG in Non REM sleep $(7.5 \mathrm{~Hz}$ to $12 \mathrm{~Hz}$ ) less than $20 \%$ and where 5 was more than $80 \%$ of alpha EEG in Non REM sleep. In order to evaluate daytime lethargy the overnight sleep study was followed by the multiple sleep latency test (MSLT) comprising of at least four 20 minute nap opportunities at 2 hour interval beginning 2 hours after morning awakening [16]. Self ratings of symptoms pre-sleep and post sleep consisted of standard measures of total regional musculoskeletal pain severity (0-24), of fatigue (1-7) [17], and sleepiness [18] that had been used in previous studies of patients with fibromyalgia syndrome (FMS) and chronic fatigue syndrome (CFS). Because clinically the post-SARS patients described many of the features seen in patients with FMS we also compared the self ratings of pain, fatigue and sleepiness symptoms and objective indices of overnight sleep physiology to an aged matched population of 21 drug free female patients, (mean age $42.4+$ /11.8 yrs.) who fulfilled criteria for fibromyalgia [19]. They had participated in a double blind placebo- controlled drug trial, to which they had provided their ethics approved signed consent. Only the initial overnight pretreatment sleep study was employed for the purposes of comparison with this post-SARS chronically ill patient population. In addition to the standard sleep physiological indices described above we analyzed another sleep EEG anomaly known as a high frequency of cyclical alternating pattern (CAP). The CAP rate has been found to be a quantified measure of EEG sleep stability where frequent periodic EEG arousal disturbances indicate sleep instability or poor quality sleep. This high frequency of CAP has been related to less efficient sleep and the severity of symptoms of patients with FMS [20,21]. Objective ratings of CAP rate was assessed using a validated, computerized automatic detection methodology (Somnologica) $[22,23]$. Statistical analyses were completed between group 2 tail t-tests for behavioural self-ratings, sleep 
physiological indices, and pre-post sleep ratings of current symptoms. Bonferroni corrections were performed on the multiple $t$ tests.

\section{Results}

In comparison to healthy subjects, post-SARS subjects reported more physical symptoms on the WPSI (mean $10.6+/-5.0$ vs. $0.4+/-0.5, \mathrm{p}<.0001)$. On most days they complained of tiredness, difficulty sleeping, myalgia and muscular weakness. They had more mild to moderate depressive symptoms $(\mathrm{BDI}$ mean $=13.3+/-8$ vs. 0.86 $+/-1.5, \mathrm{p}<.0001)$, more sleep disturbances on the $\mathrm{SAQ}^{\mathrm{c}}$ (mean total score $=30.9+/-5$ vs. $10.9+/-3.4$, $\mathrm{p}<.0001)$, more fatigue post-sleep $(\mathrm{p}<.05)$, and more myalgia pre- and post-sleep $(\mathrm{p}<.01)$. See Table 1 . For the 21 patients that completed the PCL-C, the mean score was $40.75+/-10.26$. Two patients had scores of 50 or more that would be suggestive of the symptoms seen in patients with PTSD [24].

The overnight sleep physiology in the post-SARS group showed more arousal disturbances and the alpha EEG sleep disorder which consists of the anomalous appearance of the EEG alpha frequency $(7.5-12 \mathrm{~Hz})$ in approximately $50 \%$ of sleep. There was more stage 2 NonREM sleep and a delay in onset to REM sleep, but no other significant differences in measures of sleep EEG. See Table 1.

In measures of sleep-related respiratory disturbances, 5 post-SARS subjects who snored had variable daytime sleepiness on the MSLT (defined as rapid onset to sleep in less than $8 \mathrm{~min}$ on at least one of the 4 or 5 nap opportunities, range from 3-8 min). Two of these PostSARS subjects (ages 63 yrs., BMI $=28$, and 49 yrs, BMI $=32$ ) who were being treated for hypertension had moderate and mild sleep hypopnea/apnea disorder (with a respiratory distress index $(\mathrm{RDI})=18.8$ and 8.4 respectively) and arterial oxygen desaturation (minimum of $81.2 \%$ and $83 \%$ respectively). The only other person (age 57 yrs, BMI 25.5) being treated for hypertension had very mild elevation of RDI (7.5) but no snoring, no significant sleep-related arterial oxygen desaturations or daytime sleepiness. The others had no specific disturbances in sleep-related respiration. The limited number of healthy subjects and their incomplete detailed data on REM and NonRem arterial blood oxygen saturations did not permit proper comparison with such data from the post-SARS group.

Although most complained of being depressed only two were receiving antidepressants (citalopram), one of which had sleep apnea. All patients were seen by clinical psychologists unless they declined to do so, and psychiatric consultation was available to all if requested by the patient or other team members.

In the comparison between the post-SARS \& FMS patients there were no clinically significant sleep related breathing disturbances or periodic leg movements during sleep. Both groups had a similarly elevated measure of sleep instability as indicated by the high cyclical alternating pattern rate $[22,23]$, compared to the published norms as reported by Parrino [25] et al. These are also comparable to the findings of Rizzi et al in their study of CAP in FM patients.

FMS patients, however, showed a significantly higher rating of the alpha EEG sleep anomaly than did the postSARS patients. Other than there being more NonREM stage 2 sleep and a relative delay in onset to the initial REM sleep episode there were no other differences in their stages of sleep EEG. In their ratings of somatic

Table 1 Sleep in SARS vs. Healthy Controls

\begin{tabular}{llll}
\hline Sleep Parameter & SARS & Healthy Controls & Significance \\
\hline Sleep onset latency ( min.) & Mean (SD) & Mean(SD) & P \\
\hline Total sleep time (min) & $24.13(21.63)$ & $29.34(31.48)$ & n.S. \\
\hline Sleep Efficiency \% & $370.83(83.84)$ & $343.43(38.47)$ & n.s. \\
\hline Stage 1\% & $77.44(13.56)$ & $83.23(12.36)$ & n,S. \\
\hline Stage 2\% & $9.11(4.13)$ & $6.60(4.61)$ & n.s. \\
\hline Stage 3\% & $60.22(9.95)$ & $49.77(6.53)$ & $\mathrm{p}=0.006$ \\
\hline Stage 4\% & $7.83(6.36)$ & $4.84(2.11)$ & n.S. \\
\hline REM onset Latency ( min.) & $6.27(5.80)$ & $9.70(2.84)$ & $\mathrm{p}=0.051$. \\
\hline REM \% & $136.79(63.72)$ & $87.23(38.47)$ & $\mathrm{p}=0.004$ \\
\hline Apnea/Apnea-Hypopneas Index (no. per hr.of sleep) & $16.57(5.94)$ & $17.27(5.35)$ & n.S. \\
\hline REM Apnea-Hypopnea Index (no. per hr.of REM sleep) & $4.70(5.53)$ & $14.33(15.41)$ & n.S. \\
\hline NREM 02 saturation (max/min) & $99.13(0.68) 92.09(3.61)$ & N/A & N/A \\
\hline REM 02 saturation (max/min) & $98.69(0.93) / 92.24(4.60)$ & N/A 96.50 (0.71) & N/A \\
\hline
\end{tabular}


symptoms post-SARS patients reported pre and post sleep fatigue and sleepiness similar to that reported by patients with FMS. Unlike the FMS patients they complained of less pre sleep and post sleep musculoskeletal pain symptoms (see table 2). See Table 2.

\section{Discussion}

This is the first report of the long-term adverse effects of widespread chronic pain, fatigue, psychological distress and disturbed sleep after acute SARS that contributed to the failure to return to productive work of a small cohort of health care professionals at least one year after their acute illness. After their initial SARS symptoms of severe respiratory distress, fever with evidence for infiltrates in their lungs had remitted so that they were considered to be no longer in need of special quarantine and acute treatment measures, a constellation of symptoms persisted that interfered with their ability to function in their occupations. This was then a potentially biased selection process of 22 patients who were members of a group of 50 chronically ill survivors of SARS. A larger study of 107 patients from Toronto, with a more widely selected population [26] had shown that, at the one year mark some continued to describe problems with pain, reduced vitality, physical, mental, and social functioning. Only 14 (13\%) were asymptomatic, leaving 93 patients (87\%) symptomatic, where 18 (17\%) had not returned to work, and 10 (9\%) had returned to modified work. If one presumes that the asymptomatic group was most likely to return to unmodified work, then of the 79 patients returning to unmodified work, only 14 were asymptomatic. This leads to the arithmetic conclusion that 65 (82\%) of their patients who returned to unmodified work were nevertheless continuing to work despite ongoing symptoms.

Furthermore, 5 of our 22 subjects showed variable daytime sleepiness, which was associated with snoring indicative of sleep disordered breathing, but not necessarily overt sleep apnea. While sleep-related breathing disturbances have been reported in some patients with FMS/CFS [27-29] only three post-SARS subjects exhibited mild to moderate sleep apnea/hypopneas. However, they may have had this sleep disorder before SARS because they were being treated for hypertension, a common causal risk for untreated sleep apnea [30]. Nevertheless, these sleep-related respiratory disturbances together with the alpha EEG sleep disorder may have contributed to their unrefreshing sleep and daytime symptoms.

Our single overnight study showed sleep physiological changes in stage 2 and REM onset latency that may have been influenced by being a feature of the potential adverse effect on sleep of the procedures employed in the study, known as the first night effect. The groups, however, were compared under similar circumstances although the SARS healthcare subjects may have been

Table 2 Sleep, Pain and Fatigue in SARS vs. FMS Subjects

\begin{tabular}{|c|c|c|c|}
\hline Sleep Parameter & SARS $(n=22)$ & Fibromyalgia $(n=21)$ & Significance \\
\hline & Mean (SD) & Mean (SD) & \\
\hline Sleep onset latency ( min.) & $24.13(21.63)$ & $18.37(35.39)$ & n.s. \\
\hline Total sleep time (min) & $370.83(83.84)$ & $338.54(76.26)$ & n.s. \\
\hline Sleep Efficiency \% & $77.44(13.56)$ & $79.34(15.63)$ & n.s. \\
\hline Stage $1 \%$ & $9.11(4.13)$ & $9.76(3.66)$ & n.s. \\
\hline Stage $2 \%$ & $60.22(9.95)$ & $54.61(5.41)$ & 0.031 \\
\hline Stage $3 \%$ & $7.83(6.36)$ & $7.35(3.08)$ & n.s. \\
\hline Stage $4 \%$ & $6.27(5.80)$ & $9.53(6.18)$ & n.s. \\
\hline REM onset Latency ( min.) & $136.79(63.72)$ & $87.26(35.78)$ & 0.004 \\
\hline REM \% & $16.57(5.94)$ & $18.77(4.81)$ & n.s. \\
\hline Apnea/Hypopneas Index (no. per hr.of sleep) & $4.70(5.53)$ & $3.29(2.37)$ & n.s. \\
\hline Periodic leg movements ( no.per hr of sleep) & $2.03(5.64)$ & $2.38(3.81)$ & n.s. \\
\hline Arousals per hr of sleep & $14.01(7.59)$ & $11.31(5.31)$ & n.s. \\
\hline CAP rate per hr of sleep & 71.64()$(14.25)$ & $70.39(15.64)$ & n.s. \\
\hline Alpha EEG sleep (1-5) & $3.00(0.63)$ & $3.50(0.61)$ & 0.014 \\
\hline Presleep Pain Presleep Fatigue (1-7) & $6.24(4.01) 4.57(1.57)$ & $10.95(5.74) 4.30(1.08)$ & 0.005 n.s. \\
\hline Presleep Sleepiness (1-7) & $2.76(1.14)$ & $4.30(1.08)$ & 0.0001 \\
\hline Post Sleep Pain (0-24) & $7.10(3.81)$ & $11.75(6.45)$ & 0.009 \\
\hline Post Sleep Fatigue (1-7) & $4.30(1.87)$ & $4.60(1.23)$ & n.s. \\
\hline Post Sleep Sleepiness (1-7) & $3.45(1.57)$ & $3.90(1.12)$ & n.s. \\
\hline
\end{tabular}


more sensitive to being tested in the sleep laboratory, and being more depressed. The two who were receiving antidepressant medications (citalopram) did not differ in any of the sleep parameters from the others who were equally depressed and not receiving such medications.

In our cohort, their disabling chronic fatigue, variable nonspecific myalgia, depression and sleep disturbances are similar to those experienced by patients with postfebrile Chronic Fatigue Syndrome (CFS) [31] and Fibromyalgia Syndrome (FMS) [32]. Indeed, physiological changes in their sleep EEG, i.e., the alpha EEG sleep anomaly is a common feature in such patients who commonly complain of unrefreshing sleep, fatigue, musculoskeletal pain, impaired cognitive functioning, and emotional distress [21,23,33-36]. In the comparison of the post-SARS patients to the FMS subjects we noted similar sleep EEG elevated cyclical alternating pattern rate as previously reported by ourselves and others $[22,23]$. However, in this study both the alpha EEG sleep ratings and the pain ratings were greater in FMS disorder than the post-SARS patients. Indeed the postSARS patients seem to be similar to CFS patients where their focus is on fatigue symptoms rather than the pain.

Some contribution to the post-SARS persistent sleep, pain, fatigue, and depressive symptoms may have occurred as the result of the psychologically traumatic effects of their acute infectious illness. That is, these symptoms may have arisen as the result of their isolation from family and friends, uncertain outcome and threat of death. While as a group the post-SARS patients did rate themselves as having psychological distress only 2 patients described features on the PCL-C rating scale that are attributed to those with PTSD [12]. Such distressing experiences together with their acute SARS may have contributed to their alpha EEG arousal disturbances in sleep, recurrent nightmares and their inability to obtain restful sleep. Sleep difficulties have been reported in health care workers who did not have SARS themselves, but who did care for patients with SARS [37]. Indeed, similar unrefreshing sleep, fatigue and musculoskeletal pain symptoms occur in healthy people who have been experimentally exposed to several nights of frequent noise induced disruption of slow wave sleep, which artificially produces the periods of the alpha EEG sleep [38].

In addition there is the possibility that the sleep disorder, fatigue and behavioral symptoms may have occurred as the result of the Coronavirus A directly; this virus is known to invade the central nervous system and peripheral tissues $[39,40]$. Viral particles and viral genome sequences were isolated from the cytoplasm of neurons more commonly in the hypothalamus and the cortex $[41,42]$. Although the evidence indicates that the virus crosses the blood-brain barrier into the brain, the route of infection in humans remains unknown [43]. In mice that are transgenic for the SARS-CoV receptor (human angiotensin-converting enzyme 2) the virus enters the brain primarily via the olfactory bulb. Thereafter the infection spreads rapidly via neurons throughout the brain [44]. The virus may have resulted in chronic postinflammatory CNS pathology that adversely affects sleep, pain sensitivity, and energy. In previous studies of

Table 3 Published Studies

\begin{tabular}{|c|c|c|}
\hline \multicolumn{3}{|c|}{ re Patients Post-SARS (re Sleep) } \\
\hline Location & Followup Time & Outcomes \\
\hline \multirow[t]{4}{*}{ Toronto } & Acute illness (Retrospective) & no discussion sleep [2] \\
\hline & 21 day & no discussion of sleep [1] \\
\hline & 3 weeks post discharge & Appears to be $100 \%$ prevalence insomnia (two cases were severe) [4] \\
\hline & One year & complaints of sleep disturbance averaging $47 \%$ prevalence [26] \\
\hline \multirow[t]{4}{*}{ Asia } & "peak of outbreak" & Sleep problems noted, no incidence given [50] \\
\hline & 6 months & No discussion sleep [51] \\
\hline & Summary 2005 & No discussion sleep [52] \\
\hline & Summary 2006 & No discussion sleep [53] \\
\hline \multicolumn{3}{|c|}{ re Health Care Workers Not III With SARS (re Sleep) } \\
\hline \multirow[t]{3}{*}{ Toronto } & 4 weeks & No prevalence given, but "sleep may be the first casualty"[54] \\
\hline & $\sim 5$ months & "Stigma, fear, frustration" but no discussion sleep [55] \\
\hline & 26 months & Negative psychological effects but no discussion sleep [56] \\
\hline \multirow[t]{4}{*}{ Asia } & 5 weeks & No discussion sleep [57] \\
\hline & April, May 2003 & No discussion sleep [58] \\
\hline & 3 months & Sleep "poor", improved by prevention program [37] \\
\hline & 30 months & "Mental health catastrophe" but no discussion sleep [59] \\
\hline
\end{tabular}


chronic post-viral fatigue, both severity of the initial illness [45] and symptom-attributional style and physician behaviour [46] have been associated with such outcomes.

The literature regarding SARS has documented many physical and psychological sequelae of the illness in both the short and the long term. Many studies did not note sleep disturbances, most likely on the basis that the focus of the study was elsewhere, even when one would expect sleep disturbances - such as when reporting incidence of post traumatic stress disorder (PTSD). In the studies where questions were asked about sleep, sleep disturbances were noted, although prevalence numbers are hard to find (table 3).

\section{Conclusions}

Chronic post-SARS is characterized by persistent fatigue, diffuse myalgia, weakness, depression, and nonrestorative sleep with associated REM-related apneas/hypopneas and alpha EEG sleep disorder. These clinical and sleep features of chronic post-SARS are similar to those features which may be found in patients with chronic fatigue syndrome/fibromyalgia. This report of the possible contribution of the coronaviral SARS to the emergence of chronic fatigue, unrefreshing sleep fatigue and widespread musculoskeletal pain symptoms also raises the question of the specificity the infectious retrovirus, XMRV, in blood cells that was recently reported [47] but is now a source of controversy as to its significance and specificity for patients with chronic fatigue syndrome $[48,49]$. A longer term, large scale study is needed to establish the contribution of epidemic and pandemic viral disease to the disordered sleep, chronic fatigue and somatic symptoms of chronic fatigue/fibromyalgia syndrome.

\section{Acknowledgements \\ The Workplace Safety and Insurance Board of Ontario provided the clinical treatment program (including sleep studies) for these patients and the Toronto Psychiatric Research Foundation provided support for the research. Neither organization had any role in the design/conduct of the study; the collection, analysis, and interpretation of neither the data; nor the preparation or review of the manuscript. \\ We wish to acknowledge the contribution of Vela Pharmaceuticals ( now Tonix Pharmaceuticals) for providing initial support for obtaining the drug free sleep EEG and symptom information on the patients who consented to being screened for fulfilling American College of Rheumatology criteria as preliminary to an ethics approved double blind placebo-controlled drug study for the treatment of fibromyalgia at the Sleep Disorders Clinic of the Centre for Sleep and Chronobiology in Toronto; the assistance of the technical and administrative staff of the Sleep Disorders Clinic of the Centre for Sleep and Chronobiology and St. John's Rehabilitation Hospital. Most particularly, we wish to thank all the post-SARS patients who, despite their ongoing personal difficulties, gave permission to use their data.}

\section{Author details}

${ }^{1}$ Sleep Disorders Clinic of the Centre for Sleep and Chronobiology, 340 College St., Suite 580, Toronto, ON M5T 3A9, Canada. ${ }^{2}$ St. John's Rehab Hospital, 285 Cummer Ave, Toronto, ON M2M 2G1, Canada. ${ }^{3}$ Department of Medicine, University of Toronto, \#3S805 - 200 Elizabeth Street, Toronto, ON M5G 2C4 Canada.

\section{Authors' contributions}

Both authors had a physician-patient relationship with all patients in this study, and clinically reviewed the data for each patient as the sleep studies were done. HM did the initial data analysis, which was then reviewed by both authors. The first draft was written primarily by HM with some sections by JP, and extensively discussed, re-worked and edited by both authors. Reference contributions were from both. Both authors read and approved the final draft.

\section{Competing interests}

For Dr. Patcai - nil. Dr. Moldofsky is a consultant to, or is on the advisory boards of, or has received speakers honoraria, and/or research support from Eli Lilly, Jazz, Tonix (Krele), Lundbeck, Merck, Pfizer, Pierre Fabre, Sanofi Aventis, Schering Plough and Valeant.

Received: 8 April 2010 Accepted: 24 March 2011

Published: 24 March 2011

\section{References}

1. Booth CM, Matukas LM, Tomlinson GA, Rachlis AR, Rose DB, Dwosh HY, et al: Clinical Features and Short-term Outcomes of 144 Patients With SARS in the Greater Toronto Area. JAMA 2003, 289:2801-2809.

2. Muller MP, Richardson SE, McGeer A, Dresser L, Raboud J, Mazzulli T, et al: Early diagnosis of SARS: lessons from the Toronto SARS outbreak. Eur J Clin Microbiol Infect Dis 2006, 25:230-237.

3. McDonald LC, Simor AE, Su IJ, Malone S, Ofner M, Chen KT, et al: SARS in healthcare facilities, Toronto and Taiwan. Emerg Infect Dis [serial on the Internet] 2004 [http://www.cdc.gov/ncidod/EID/vol10no5/03-0791.htm].

4. Avendano M, Derkach P, Swan S: Clinical course and management of SARS in health care workers in Toronto: a case series. CMAJ 2003, 168(13):1649-1660.

5. Ksiazek TG, Erdman D, Goldsmith CS, Zaki SR, Peret T, Emery S, et al: A novel coronavirus associated with severe acute respiratory syndrome. $N$ Engl J Med 2003, 348:1953-66.

6. Marra MA, Jones SJM, Astell CR, Holt RA, Brooks-Wilson A, Brooks-Wilson A, Butterfield, Yaron SN, et al: The Genome Sequence of the SARSAssociated Coronavirus. Science 2003, 300:1399-1404.

7. Hamming I, Timens W, Bulthuis ML, Lely AT, Navis GJ, van Goor H: Tissue distribution of ACE2 protein, the functional receptor for SARS coronavirus. A first step in understanding SARS pathogenesis. Journal of Pathology 2004, 203(2):631-7.

8. Low DE, McGeer A: SARS-one year later. New Engl J Med 2003, 349(25):2381-2.

9. Wahler HR: The physical symptoms inventory: measuring levels of somatic complaining behavior. J Clin Psychol 1968, 24:207-211.

10. Beck AT, Ward CH, Mendelson M, Monk M, Erbaugh J: An inventory for measuring depression. Arch Gen Psychiatry 1961, 4:561-571.

11. Beck AT, Rial WY, Rickels K: Short form of depression inventory: crossvalidation. Psychological Reports 1974, 34:1184-6.

12. Blanchard EB, Jones-Alexander J, Buckley TC, Forneris CA: Psychometric properties of the PTSD Checklist (PCL). Behav Res Ther 1996, 34:669-73.

13. Unger ER, Nisenbaum R, Moldofsky H, Cesta A, Sammut C, Reyes M, et al: Sleep assessment in a population-based study of chronic fatigue syndrome. BMC Neurol 2004, 4(1):6.

14. Rechtshaffen A, Kales A: A manual of standardized terminology, techniques and scoring system for sleep stages of human subjects. UCLA Brain Info Serv/Brain Res Inst, LA 1968.

15. MacLean AW, Lue F, Moldofsky H: The reliability of visual scoring of alpha EEG activity during sleep. Sleep 1995, 18:565-9.

16. van den Hoed J, Kraemer H, Guilleminault C, Zarcone VP Jr, Miles LE, Dement WC, et al: Disorders of excessive daytime somnolence: polygraphic and clinical data for 100 patients. Sleep 1981, 4:23-37.

17. Moldofsky H, Saskin P, Lue FA: Sleep and symptoms in fibrositis syndrome after a febrile illness. J of Rheumatol 1988, 15(2):1701-1704.

18. Hoddes E, Zarcone V, Smythe H, Phillips R, Dement WC: Quantification of sleepiness: a new approach. Psychophysiology 1973, 10:431-6.

19. Wolfe F, Smythe HA, Yunus MB, Bennett RM, Bombardier C, Goldenberg DL, et al: The American College of Rheumatology 1990 criteria for the classification of fibromyalgia: report of the multicenter criteria committee. Arthritis Rheum 33(160-172):1990. 
20. Rizzi M, Sarzi-Puttini P, Atzeni F, Capsoni F, Andreoli A, Pecis M, et al: Cyclical Alternating Pattern: A new marker for sleep alteration in patients with fibromyalgia. J Rheumatol 2004, 34:1193-99.

21. Moldofsky H, Inhaber NH, Guinta DR, Alvarez-Horine SB: The Effects of Sodium Oxybate on Sleep Physiology and Sleep/Wake-Related Symptoms in Patients with Fibromyalgia Syndrome: A double-blind, randomized, placebo-controlled study. J Rheumatol 2010, 37:2156-66, Epub 2010 Aug 3.

22. Rosa AC, Parrino L, Terzano MG: Automatic detection of cyclic alternating pattern (CAP) sequences in sleep: preliminary results. Clin Neurophysiol 1999, 110:585-92.

23. Rosa A, Alves GR, Brito M, Lopes MC, Tufik S: Visual and automatic cyclic alternating pattern (CAP) scoring: inter-rater reliability study. Arq Neuropsiquiatr 2006, 64:578-81.

24. Weathers F, Ford J: Psychometric properties of the PTSD Checklist (PCL-C, PCL-S, PCL-M, PCL-PR). In Measurement of Stress, Trauma, and Adaptation. Edited by: Stamm BH. Lutherville, Md: Sidran Press; 1996.

25. Parrino L, Boselli M, Spaggiari MC, Smerieri A, Terzano MG: Cyclic alternating pattern (CAP) in normal sleep: polysomnographic parameters in different age groups. Electroencephalography \& Clinical Neurophysiology 1998, 107:439-50.

26. Herridge MS, Cheung AM, Tansey CM, Matte-Martyn A, Diaz-Granados N, AlSaidi F, et al: One-Year Outcomes In Survivors Of The Acute Respiratory Distress Syndrome. N Engl J Med 2003, 348:683-93.

27. May KP, West SG, Baker MR, et al: Sleep apnea in male patients with fibromyalgia syndrome. Am J Med 1993, 94:505-508.

28. Sergi M, Rizzi $M$, Braghiroli $A$, et al: Periodic breathing during sleep in patients affected by fibromyalgia syndrome. Eur Respir $J$ 1999, 14:203-208.

29. Gold AR, Dipalo F, Gold MS, Broderick J: Inspiratory airflow dynamics during sleep in women with fibromyalgia. Sleep 2004, 27:459-466.

30. Grote L, Ploch T, Heitmann J, Knaack L, Penzel T, Peter JH: Sleep-related breathing disorder is an independent risk factor for systemic hypertension. Am J Respir Crit Care Med 1999, 160:1875-1882.

31. Fukuda K, Straus SE, Hickie I, Sharpe MC, Dobbins JG, Komaroff A, et al: The chronic fatigue syndrome: a comprehensive approach to its definition and study. Ann Int Med 1994, 121:953-959.

32. Wolfe F, Smythe HA, Yunus MB, Bennett RM, Bombardier C, Goldenberg DL, et al: The American College of Rheumatology 1990 criteria for the classification of fibromyalgia: report of the multicenter criteria committee. Arthritis Rheum 1990, 33:160-172.

33. Branco J, Atalaia A, Paiva T: Sleep cycles and alpha-delta sleep in fibromyalgia syndrome. Journal of Rheumatololog 1994, 21:1113-1117.

34. Drewes AM, Nielsen KD, Taagholt SJ, Bjerregård K, Svendsen L, Gade J: Sleep intensity in fibromyalgia: focus on the microstructure of the sleep process. Br J Rheumatol 1995, 34:629-635.

35. Roizenblatt S, Moldofsky H, Benedito-Silva AA, Tufik S: Alpha sleep characteristics in fibromyalgia. Arthritis \& Rheumatism 2001, 44:222-30.

36. Whelton CL, Salit I, Moldofsky Sleep H: Epstein-Barr virus infection, musculoskeletal pain, and depressive symptoms in chronic fatigue syndrome. Journal of Rheumatology 1992, 19:939-943.

37. Chen R, Chou K, Huang Y, Wang T, Liu S, Ho L: Effects Of A SARS Prevention Programme In Taiwan On Nursing Staff's Anxiety, Depression And Sleep Quality: A Longitudinal Survey. International Journal of Nursing Studies 2006, 43(2):215-225.

38. Moldofsky $H$, Scarisbrick P: Induction of neurasthenic musculoskeletal pain syndrome by selective sleep stage deprivation. Psychosom Med 1976, 38:35-44.

39. Glass WG, Subbarao K, Murphy B: Murphy PM. Mechanisms of host defense following severe acute respiratory syndrome-coronavirus (SARSCoV) pulmonary infection of mice. Journal of Immunology 2004, 173:4030-9.

40. He L, Ding YQ, Che XY, Zhang QL, Huang ZX, Wang HJ, et al: Expression of the monoclonal antibody against nucleocapsid antigen of SARSassociated coronavirus in autopsy tissues from SARS patients. Di Yi Junyi Daxue Xuebao 2003, 23:1128-30.

41. Gu J, Gong E, Zhang B, Zheng J, Gao Z, Zhong Y, et al: Multiple organ infection and the pathogenesis of SARS. J Exp Med 2005, 202:415-424.

42. Xu J, Zhong S, Liu J, Li L, Li Y, Wu X, et al: Detection of severe acute respiratory syndrome coronavirus in the brain:potential role of chemikine mig in pathogenesis. Clin Infect Dis 2005, 41:1089-1096.
43. Yong G, Kortweg C, McNutt MA, Gu J: Pathogenetic mechanisms of severe acute respiratory syndrome. Virus Research 2008, 133:4-12.

44. Netland J, Meyerholz DK, Moore S, Cassell M, Perlman S: Severe acute respiratory syndrome coronavirus infection causes neuronal death in the absence of encephalitis in mice transgenic for human ACE2. J Virol 2008, 82:7264-75.

45. Hickie I, Davenport T, Wakefield D, Vollmer-Conna U, Cameron B, Vernon SD, et al: Dubbo Infection Outcomes Study Group. Post-infective and chronic fatigue syndromes precipitated by viral and non-viral pathogens: prospective cohort study. BMJ 2006, 333(7568):575.

46. Cope H, David A, Pelosi A, Mann A: Predictors of chronic "postviral" fatigue. The Lancet 1994, 344:8926.

47. Lombardi V, Ruscetti FW, Gupta JD, Pfost MA, Hagen KS, Peterson DL, et al: Detection of an Infectious Retrovirus, XMRV, in Blood Cells of Patients with Chronic Fatigue Syndrome. Science 2009, 326:585-589.

48. van der Meer JWM, Netea MG, Galama JMD, van Kuppeveld FM: Comment on "Detection of an Infectious Retrovirus, XMRV, in Blood Cells of Patients with Chronic Fatigue Syndrome". Science 2010, 328, 825.

49. Hue S, Gray ER, Gall A, Katzourakis A, Tan CP, Houldcroft CJ, et al: Diseaseassociated XMRV sequences are consistent with laboratory contamination. Retrovirology 2010.

50. Chua SE, Cheung V, Cheung C, MCAlonan GM, Wong JW, Cheung EP, et al: Stress and Psychological Impact On SARS Patients During The Outbreak. Can J Psychiatry 2004, 49:201-206

51. Hui DS, Joynt GM, Wong KT, Gomersall CD, Li TS, Antonio G, et al: Impact of Severe Acute Respiratory Syndrome (SARS) On Pulmonary Function, Functional Capacity And Quality Of Life In A Cohort Of Survivors. Thorax 2005, 60:401-409.

52. Chan JWM, Ng CK: Severe Acute Respiratory Syndrome (SARS): A Brief Review With Exploration of the Outcomes, Prognostic Factors and Sequelae. Current Respiratory Medicine Reviews 2005, 1:85-92.

53. Chan PK, Tang JW, Hui DS: SARS: clinical presentation, transmission, pathogenesis and treatment options. Clinical Science 2006, 110:193-204.

54. Maunder R, Hunter J, Vincent L, Bennett J, Peladeau N, Leszcz M, et al: The immediate psychological and occupational impact of the 2003 SARS outbreak in a teaching hospital. CMAJ 2003, 168:1245-51.

55. Robertson E, Hershenfield K, Grace SL, Stewart DE: The psychosocial effects of being quarantined following exposure to SARS: a qualitative study of Toronto health care workers. Can J Psychiatry 2004, 49:403-407.

56. Maunder RG, Lancee WJ, Balderson KE, Bennett JP, Borgundvaag B, Evans S, et al: Long-term Psychological and Occupational Effects of Providing Hospital Healthcare during SARS Outbreak. Emerg Infect Dis 2006, 12:1924-32.

57. Lau HM, Lee EW, Wong C, Ng G, Jones A, Hui D: The Impact of Severe Acute Respiratory Syndrome on the Physical Profile and Quality of Life. Archives of Physical Medicine and Rehabilitation 2005, 86:1134-1140.

58. Chua SE, Cheung V, Cheung C, MCAlonan GM, Wong JW, Cheung EP, et al: Psychological effects of the SARS outbreak in Hong Kong on high-risk health care workers. Can J Psychiatry 2004, 49:391-3.

59. Mak IW, Chu CM, Pan PC, Yiu MG, Chan VL: Long-term psychiatric morbidities among SARS survivors. Gen Hosp Psychiatry 2009, 31:318-26.

\section{Pre-publication history}

The pre-publication history for this paper can be accessed here: http://www.biomedcentral.com/1471-2377/11/37/prepub

doi:10.1186/1471-2377-11-37

Cite this article as: Moldofsky and Patcai: Chronic widespread musculoskeletal pain, fatigue, depression and disordered sleep in chronic post-SARS syndrome; a case-controlled study. BMC Neurology 2011 11:37 